\title{
Despojo, conflictos socioambientales y violación de derechos humanos. Implicaciones de la gran minería en América Latina
}

\section{Spoliation, socio-environmental conflicts and human rights violation Implications of large scale mining in Latin America}

\author{
Luz Adriana Muñoz-Duque ${ }^{1}$; Margarita María Pérez Osorno ${ }^{2}$; Angie Betancur Vargas ${ }^{3}$
}

1Psicóloga, Esp., M.Sc., Ph.D.(c). Universidad de Antioquia, Medellín - Antioquia, Colombia; e-mail: luza.munoz@udea.edu.co; (D) https://orcid.org/00000002-9173-3802

22Administradora en Salud, Esp., M.Sc., Ph.D. Universidad de Antioquia, Medellín - Antioquia, Colombia; e-mail: margarita.perez@udea.edu.co; D https:// orcid.org/0000-0002-7178-9702

${ }^{3}$ Administradora en Salud. Universidad de Antioquia, Medellín - Antioquia, Colombia; e-mail: anibetancur@hotmail.com; (D) http://orcid.org/0000-00027662-5408

Cómo citar: Muñoz-Duque, L.A.; Pérez Osorno, M.M.; Betancur Vargas, A. 2020. Despojo, conflictos socioambientales y violación de derechos humanos. Implicaciones de la gran minería en América Latina. Rev. U.D.C.A Act. \& Div. Cient. 23(1):e988. http://doi. org/10.31910/rudca.v23.n1.2020.988

Artículo de acceso abierto publicado por Revista U.D.C.A Actualidad \& Divulgación Científica, bajo una licencia Creative Commons CC BY-NC 4.0

Publicación oficial de la Universidad de Ciencias Aplicadas y Ambientales U.D.C.A, Institución de Educación Superior Acreditada de Alta Calidad por el Ministerio de Educación Nacional.

Recibido: Octubre 16 de 2018

Aceptado: Marzo 10 de 2020

Editado por: Ingeborg Zenner de Polanía

\section{RESUMEN}

Los gobiernos latinoamericanos han impulsado al sector minero energético en sus territorios, con el propósito de atraer inversión extranjera directa. El artículo expone hallazgos de una revisión documental sobre implicaciones territoriales que, en el marco de un modelo neoliberal, ha traído consigo la implementación y el fortalecimiento de la minería a gran escala, en América Latina. A partir del análisis, se presenta información de tres categorías: principales afectaciones ambientales y sociosanitarias asociadas a la minería a gran escala, en los territorios latinoamericanos, emergencia de conflictos ambientales vinculados con la actividad y las condiciones que, dentro de los países y en relación con la minería a gran escala, favorecen la violación de derechos humanos. Se concluye sobre la relevancia de pensar la actividad extractiva a gran escala, en clave de justicia social y ambiental, poniendo en la balanza los "beneficios" que genera, pero también, las externalidades y las afectaciones que deja a su paso.

Palabras clave: minería; efectos de las actividades humanas; consecuencias para la salud; impacto ambiental; cambio social.

\section{ABSTRACT}

Latin American governments have given an important boost to the mining sector in their territories, in order to attract foreign investment. The article exposes the findings of a documentary review that sought to identify and to describe territorial implications that, within the framework of a neoliberal model, has brought with it the implementation and strengthening of large-scale mining in 
Latin America. From the analysis process, information is presented in three categories: main impacts associated with large-scale mining in Latin American territories, emergence of environmental conflicts linked to the activity and the conditions that, within the countries and in relation to the large-scale mining, favor the violation of human rights. It concludes on the relevance of thinking about the large-scale extractive activity in the key of social and environmental justice, putting in the balance the "benefits" that it generates, but also the externalities and affectations that it leaves in its wake.

Keywords: mining; human activities effects; health consequences; environmental impact; social change.

\section{INTRODUCCIÓN}

\author{
"Los gobernantes y empresarios rinden culto a la actividad minera como si \\ fuera la diosa que nos sacará de la crisis y la pobreza"
}

(SERVINDI, 2004)

Con un marcado énfasis a partir de la instauración del actual modelo socioeconómico neoliberal, la minería ha sido vista como una palanca para el desarrollo económico de las naciones (Delgado, 2010; Banco Mundial, 2013; McMahon \& Moreira, 2014; Unidad de Planeación Minero Energética, 2017). Desde esta lógica, diferentes países latinoamericanos han apostado a un desarrollo minero extractivista, sosteniendo parte de su economía en la remoción de significativos volúmenes de recursos naturales, comúnmente para la exportación. La minería ha sido concebida como posibilidad de ingreso de capital transnacional a países en vía de desarrollo, como necesaria y sinónimo de riqueza (Infante, 2011; Seoane et al. 2013; Veltmeyer \& Petras, 2014; Torres \& López, 2017).

En este escenario, se han generado iniciativas para promover la actividad a gran escala, lo cual, tiene expresión en la generación de instrumentos jurídicos, la participación gubernamental, la falta de consecuencias asociadas a los impactos socioambientales, los beneficios tributarios con los que cuentan las empresas (Gudynas, 2011; Sandoval, 2012; Grupo de Investigación en Derechos Colectivos y Ambientales, 2013; Insuasty et al. 2013). En esta vía, a partir de 1988, el Banco Mundial ha ofrecido asistencia a varios países del mundo, a través de proyectos orientados a lograr reformas en el sector. Esta entidad destaca el incremento en la inversión minera privada y extranjera y el mejoramiento de indicadores económicos: exportaciones, ingresos fiscales y producto interno bruto, de las naciones receptoras de su asistencia (Banco Mundial, 2013).

Tal fomento de la minería, también se manifiesta en la tendencia promovida por los denominados gobiernos progresistas suramericanos, a hacer uso de métodos extractivistas, considerados como posibilidad de progreso y como estrategia de reducción de la pobreza; contextos en los que, incluso, las empresas estatales siguen una lógica de rentabilidad y eficacia y donde se han multiplicado los procesos de desterritorialización derivados de la emergencia de grandes proyectos mineros, así como la movilización social, en muchos casos, criminalizada por los mismos gobiernos (Seoane \&
Taddei, 2005; Svampa, 2007; Gudynas, 2011; Composto \& Navarro, 2012; Sánchez, 2017).

De acuerdo con la clasificación propuesta por Viana Ríos (2018), según la importancia de la minería en sus economías y con su potencial minero, en Latinoamérica son pensados como países de importancia alta Chile, Perú, Bolivia, Colombia, Brasil y México, caracterizados por tener una relevante participación minera en el PIB nacional (mayor a 3,5), destacada participación en las exportaciones (mayor del 5\%) o reservas significativas de algún mineral. Por su parte, Argentina, Ecuador, Nicaragua, Guatemala, Panamá y Venezuela son considerados como de importancia media, en tanto que la participación minera en el PIB nacional es mayor de 1\% e inferior a 3,5\%; Costa Rica, Belice, El Salvador, Honduras, Paraguay y Uruguay son concebidos como de importancia baja, dada la escasa participación de la minería en su PIB nacional (menor al 1\%).

El mismo autor plantea que países, como Chile, Colombia, Ecuador, Guatemala, Nicaragua, Panamá y Perú, en sus planes nacionales de desarrollo, han establecido objetivos estratégicos en función de promover el sector minero, en cuyo marco se explicita la necesidad de lograr una minería capaz de integrar aspectos socioambientales (Viana Ríos, 2018).

Siguiendo los planteamientos de la CEPAL (2015), en Latinoamérica la minería de plata y oro desempeña un papel muy activo; esta industria representa, respectivamente, alrededor del 30 y 40 por ciento de proyectos, a nivel mundial; no obstante, pese al apoyo gubernamental y a la emergencia de políticas globales que promueven dinámicas extractivistas, asociadas a éstas, los territorios latinoamericanos han venido padeciendo deterioros en materia ambiental, social, cultural, política y económica. De acuerdo con la revisión realizada por el Grupo de Trabajo sobre Minería y Derechos Humanos en América Latina (2014), la industria minera supone un importante número de denuncias y de reclamaciones sobre transgresiones de derechos humanos, generalmente, relacionadas con daños a la infraestructura territorial, detrimento ambiental y ejecución de proyectos, sin dar cabida a consulta previa o en oposición a los intereses de la población local, que habita las zonas de influencia de estos proyectos.

El presente artículo da cuenta de una revisión, cuyo propósito fue identificar y describir implicaciones territoriales derivadas de la implementación y el fortalecimiento de economías basadas en lógicas extractivistas en América Latina, que favorecen a industrias extranjeras, posibilitando la explotación de los recursos naturales, que se constituyen en el patrimonio de los pueblos nativos, manteniéndose la herencia colonial extractivista (Poveda, 2015). Para hacer referencia a tales implicaciones, es preciso explicitar aquello a lo que se alude con la categoría de territorio. Para efectos del estudio, el territorio es entendido como construcción social, como una imbricación de dimensiones físicas y manifestaciones sociales, como dinámico y atravesado por relaciones de poder (Monnet, 1999; Lindón, 2002); consecuentemente, abordar un fenómeno implica territorializarlo y comprenderlo en situación. 


\section{MATERIALES Y METODOS}

Con este propósito, se llevó a cabo un estudio descriptivo de revisión documental de fuentes institucionales y de bases de datos bibliográficas. La búsqueda consideró textos en idiomas español e inglés, de acceso libre y publicados entre 2000 y 2018, en los cuales, se pudieran rastrear trabajos orientados a mostrar implicaciones socioambientales y sanitarias, asociadas a la presencia de la gran minería, en territorios latinoamericanos.

Los textos institucionales fueron rastreados en páginas oficiales: Banco Mundial -BM-, Organización Mundial de la Salud -OMS-, Observatorio de Conflictos Mineros de América Latina -OCMAL-, Centro de Estudios Políticos para las Relaciones Internacionales y el Desarrollo -CEPRID- y Comisión Económica para América Latina y el Caribe -CEPAL-. Igualmente, se exploraron publicaciones científicas en bases de datos bibliográficas electrónicas, como Dialnet, PubMed, Ebsco, Redalyc y Scielo. La estrategia de búsqueda incluyó combinaciones de descriptores, como minería a gran escala y América Latina, minería e impactos, minería y políticas extractivistas, minería y conflictos.

Tras la selección de literatura, se documentó la información por medio de una matriz de revisión bibliométrica (en Microsoft Excel) en función de lograr observaciones integradoras de los datos; esta ficha incluyó datos, como fuente, autor o autores, año, país, idioma, objetivos, resultados relacionados con el tema objeto de análisis. Los textos hallados tuvieron una revisión inicial para asegurar que cumplieran con los criterios de inclusión definidos. Posteriormente, en el proceso de análisis, se realizó una categorización a partir de principales impactos asociados a la minería a gran escala en los territorios latinoamericanos, emergencia de conflictos ambientales vinculados con la actividad y las condiciones que, dentro de los países y en relación con la minería a gran escala, favorecen la violación de derechos humanos. Estas categorías son descritas a continuación.

\section{RESULTADOS Y DISCUSIÓN}

En principio, cabe señalar que fueron identificados 110 textos, de los cuales, para el análisis, se seleccionó el 64\%; en el proceso fueron descartados 39 documentos, porque no se ajustaron a los criterios de inclusión definidos. La mayoría de los textos elegidos (95,7\%) estaban escritos en español y su publicación se concentró, principalmente, entre 2011 a 2015 (56,3\%) y 2016 a 2018 (21,1\%); los demás (publicados entre 2001 y 2010), representaron el 22,6\%.

\section{Implicaciones de la minería a gran escala en países latinoamericanos}

En los proyectos mineros analizados por el Grupo de Trabajo sobre Minería y Derechos Humanos en América Latina (2014), específicamente en los países de Argentina, Chile, Colombia, El Salvador, Guatemala, Honduras, México, Panamá y Perú, se destacan una serie de impactos ambientales y socioculturales generados tras la incursión de la minería a gran escala en los territorios: a nivel ambiental, daños relacionados con la contaminación del aire, las aguas y el suelo; a nivel sociocultural, fragmentación del tejido social de las comunidades; a nivel socioeconómico, afectaciones financieras en las zonas cercanas a los proyectos mineros tras las transformaciones de hábitos, tradiciones de vida y fuentes de ingreso monetario; asimismo, afectaciones a la salud por diversas vías.

Principales afectaciones asociadas a la minería a gran escala en territorios latinoamericanos. La minería a gran escala ha estado relacionada con afectaciones en diferentes dimensiones. Situaciones, como las presiones que las empresas mineras, ejercen directamente sobre los territorios, las alteraciones ecológicas, derivadas de la presencia de multinacionales, que impiden el desarrollo de la vida y la necesidad de imponer la práctica industrializada sobre la minería artesanal, han generado procesos de desplazamientos forzados y desterritorialización (Gudynas, 2011; Betancur \& Pérez, 2016b). También han sido descritos otros procesos asociados a la presencia y fortalecimiento de la minería a gran escala en los territorios, los cuales, se presentan en el cuadro 1.

Cuadro 1. Procesos asociados a la presencia y fortalecimiento de la minería a gran escala, en territorios latinoamericanos.

\begin{tabular}{|c|c|c|c|}
\hline \multirow{8}{*}{ 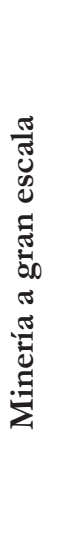 } & \multirow{5}{*}{ Impactos comunitarios } & División de las comunidades & \multirow{3}{*}{ Referencias: } \\
\hline & & Fractura del tejido social & \\
\hline & & Criminalización de la protesta social & \\
\hline & & Homicidios & \multirow{5}{*}{$\begin{array}{l}\text { Sandoval, 2012; Benavides, } \\
\text { 2014; Grupo de Trabajo } \\
\text { sobre Minería y Derechos } \\
\text { Humanos en América Latina, } \\
\text { 2014; Pérez Osorno, 2015; } \\
\text { Betancur \& Pérez, 2016a }\end{array}$} \\
\hline & & Pérdida de modos tradicionales de vida y de trabajo & \\
\hline & \multirow{2}{*}{ Económicos } & Afectaciones económicas & \\
\hline & & Apropiación fraudulenta de propiedades & \\
\hline & Socio - ambientales & Incremento de conflictos socioambientales & \\
\hline
\end{tabular}


Incursionar en un modelo neoextractivista sustentado en el Consenso de los "Commodities", ha traído ventajas comparativas para algunos, ligadas al crecimiento económico; sin embargo, son claras las asimetrías sociales y los conflictos político - culturales que la minería a gran escala deja a su paso en los territorios donde se instala. Como lo describen algunas investigaciones, la lógica de ocupación de los mismos ha tenido una intención destructiva; sobre la base de una concepción productivista y eficientista del desarrollo, se estimula la descalificación de otras formas de valorización de los territorios, que son considerados como socialmente vaciables o, simplemente, como «áreas de sacrificio», en aras del progreso selectivo (Svampa, 2013).

De acuerdo con Solíz (2016), las crisis del capital europeo y norteamericano han motivado la instalación de megaproyectos mineros en América Latina, encontrando terrenos abonados en términos de legislaciones débiles, tanto del país emisor como el receptor y bonanzas minerales en países receptores, carentes de encadenamientos productivos, lo cual, deriva en procesos de colonización, acumulación de capital y despojo de pueblos y territorios.

Desde el punto de vista sanitario, aunque de acuerdo con Fierro (2013), la información acerca de los efectos de la minería en materia de salud es precaria y se encuentra fragmentada, las fuentes revisadas han descrito problemáticas sanitarias en poblaciones asentadas alrededor de sitios de explotación minera y en los trabajadores de las minas, enfermedades neurológicas, respiratorias, transmisibles, dérmicas, gástricas, intoxicación por metales pesados y gases, contaminación auditiva relacionada con el uso de dinamita (Idrovo et al. 2001; Goyzueta \& Trigos, 2009; Astete et al. 2010; Angulo et al. 2011; Ospina et al. 2011; CEPRID, 2013; Olivero, 2014). Por su parte, los menores de edad se ven afectados por la inhalación de vapores de mercurio metálico, la ruta de exposición más preocupante; estos son absorbidos a nivel pulmonar y de allí son transferidos a la circulación sanguínea; los seres en formación durante la gestación y la primera infancia son los más susceptibles, pues la exposición crónica a mercurio metálico puede ocasionar problemas de neurodesarrollo y aprendizaje (Bose-O'Reilly et al. 2010).

En términos ecológicos, se han descrito impactos, como un uso extensivo de tierra, el empleo intenso de fuentes hídricas, el uso de cantidades considerables de energía, el incremento en la emisión de gases tóxicos, la desviación del cauce de ríos, contaminación de fuentes hídricas por empleo de metales pesados, disminución de corrientes de agua superficiales y subterráneas, generación de aguas ácidas de mina, destrucción de cerros, afectación de capas vegetales no recuperables, del suelo, de áreas cultivables y de bosque natural (Orozco, 2008; CEPRID, 2013; Saade, 2013; Pérez \& Betancur, 2016a, 2016b). Así, por ejemplo, en países, como Argentina, Honduras, Chile, Panamá, Perú y Guatemala, se ha descrito un patrón de daño de tipo ambiental por contaminación en fuentes de agua, derivado de las acciones de empresas mineras canadienses en los territorios (Grupo de Trabajo sobre Minería y Derechos Humanos en América Latina, 2014).
Desde la perspectiva de Cabrera \& Fierro (2013), las afectaciones ambientales asociadas a la gran minería implican potenciales problemas sanitarios, así como riesgos para la soberanía alimentaria de las comunidades, especialmente, aquellas cuyos ingresos económicos dependen de sus propios cultivos.

Minería a gran escala y emergencia de conflictos socioambientales. Siguiendo a Infante (2011), en países latinoamericanos el incremento de concesiones mineras ha estado acompañado de un aumento de conflictos socioambientales, ya que las comunidades apuestan a aquellos modos de vida que les resultan tradicionales; se movilizan por los ecosistemas y recursos naturales, por su seguridad, subsistencia, soberanía y justicia socio-ambiental (Isla, 2002; Alayza, 2009; Bebbington \& Humphreys, 2009; Isaza, 2016).

En México, Perú y Colombia, los conflictos generados por proyectos mineros son principalmente entre empresas mineras y comunidades afectadas por su actividad, en disputas por los territorios dados, los desplazamientos y las reubicaciones; usos (por las empresas) de lugares cargados de significados, representativos para los pobladores; transformaciones en los usos de los espacios; violaciones a derechos humanos; impactos ambientales e incumplimiento de compromisos derivados de políticas de responsabilidad social corporativa. También, se dan conflictos entre distintos niveles de gobierno, en pugnas por la distribución de rentas mineras (Saade, 2013). La minería a gran escala, concebida como base de crecimiento económico para las naciones, implica luchas por el control del negocio extractivo, que no han sido necesariamente reconocidas (CINEP, 2012).

En el caso colombiano, por ejemplo, los grupos mayormente afectados por estos conflictos son las comunidades campesinas, indígenas y afrodescendientes, quienes perciben impactos en sus medios de subsistencia, sus culturas, su salud y sus derechos territoriales (Pérez-Rincón, 2014). Para Cabrera \& Fierro (2013), los conflictos por la tenencia de tierra en el país son consecuencias comunes a la extracción de los diferentes productos minerales y energéticos existentes en su geografía. De cara al accionar de las empresas mineras, las poblaciones mismas han estimulado la organización y la movilización social, con el propósito de detener total o parcialmente algunos proyectos; contexto, en el cual, la unión de intereses comunitarios ha jugado un papel importante en la lucha por la defensa de derechos en los territorios (Sandoval, 2012; Delgado, 2013; Pérez-Rincón, 2014).

Los mecanismos de expropiación que usan los proyectos mineros son contundentes, generalmente, más que los recursos que tienen las comunidades para hacer valer sus derechos y manifestar sus inconformidades y su rechazo a estos proyectos. Los primeros están respaldados por disponibilidad de recursos económicos y apoyo gubernamental; en el segundo caso, además de recursos restringidos, hay temor a retaliaciones y gobiernos que dan la espalda a las realidades locales.

Vale la pena señalar que en Colombia, para el 2016, la Corte Constitucional, a través de la Sentencia T-445, otorgó a los entes 
territoriales la competencia para la regulación del uso del suelo y para garantizar la protección ambiental, incluso, si al hacerlo terminaban prohibiendo la actividad minera (Corte Constitucional Colombiana, 2016); no obstante, en octubre de 2018, la misma Corte emitió la Sentencia SU095/18, en la cual, planteó la existencia de límites al mecanismo de participación ciudadana denominado consulta popular, en la medida en que su alcance no puede ser prohibir actividades extractivas en un determinado territorio, toda vez que, en el país, el Estado es el propietario del subsuelo. En este sentido, las decisiones asociadas a la exploración y explotación de recursos naturales no renovables, deben ser tomadas de manera coordinada y concurrente por las autoridades nacionales con la participación de las autoridades locales (Corte Constitucional Colombiana, 2018).

En este escenario, aunque la Corte concibe que en Colombia no existen mecanismos idóneos y contundentes para garantizar la participación ciudadana (Corte Constitucional Colombiana, 2018), hay municipios donde se han llevado a cabo procesos de consulta popular para rechazar la incursión de la gran minería en sus territorios; sin embargo, se ha evidenciado la intención del gobierno de no aceptar los resultados de estas consultas.

De acuerdo con Walter \& Urkidi (2014), entre 2002 y 2012, se llevaron a cabo 68 consultas comunitarias sobre minería metálica en Argentina, Guatemala, Colombia y Perú, que evidenciaron, en todos los casos, gran oposición de las comunidades a los proyectos mineros. Estas consultas no estuvieron promovidas desde los gobiernos Nacionales, sino por movimientos que trabajan en pro de la justicia ambiental, apoyados por gobiernos locales; fueron llevadas en cabo en situaciones de criminalización y violencia, como posibilidad de reivindicación del derecho a la participación de poblaciones afectadas por proyectos mineros, que amenazan sus modos de vida.

Condiciones que propician la violación de derechos humanos. De acuerdo con los casos analizados por el Grupo de Trabajo sobre Minería y Derechos Humanos en América Latina (2014), existen una serie de condiciones internas que, asociadas a las lógicas extractivistas en los países de la región, favorecen la violación de los derechos humanos de las poblaciones. Estas condiciones están vinculadas a la normatividad y marcos legislativos débiles, así como dificultades en su implementación y ejecución; irrespeto a los derechos colectivos de los pueblos afrodescendientes, indígenas y campesinos, como también a los territorios naturales protegidos; carencia de mecanismos que garanticen la participación real de los ciudadanos afectados y ausencia de respuestas de los organismos de control que, en muchos casos, se encuentran ausentes o son poco eficientes.

Siguiendo a Sánchez-Albavera \& Lardé (2006), las legislaciones de los países latinoamericanos declaran a los Estados como dueños absolutos del subsuelo, como únicos poseedores de las riquezas mineras de cada nación; así también, consideran el desarrollo de la minería como de interés y utilidad pública. A partir de esta última idea, promueven actividades extractivas a gran escala, como medio de soporte económico, propiciando escenarios favorables para la ejecución de proyectos mineros y obviando las particularidades de las comunidades impactadas.

Es evidente la legitimación política de las prácticas extractivas a gran escala, expresada en flexibilidad jurídica, en la posibilidad de las empresas de encontrar mano de obra barata y en abundancia (en contextos con altos índices de desempleo y ocupación informal), la falta de consecuencias por las afectaciones socioambientales y los beneficios tributarios, otorgados por los países a las empresas (Gudynas, 2011; Sandoval, 2012; Insuasty et al. 2013).

El cuadro 2 sintetiza los impactos de proyectos mineros de gran escala, en algunos países latinoamericanos.

Considerando los planteamientos anteriores y de acuerdo con Pardo (2013), la globalización de economías, las declaraciones del Consenso de Washington, las presiones gremiales y los intereses de algunos críticos de las intervenciones estatales en materia minera, sentaron las bases para la modificación del Código de Minas en Colombia; así también, en otros países latinoamericanos, en la década de 1990, hubo reformas mineras inspiradas en lineamientos del Banco Mundial, entidad que planteaba regímenes fiscales estables, como garantía para los inversionistas extranjeros, asunto por el cual, diferentes naciones se vieron involucradas en reformas tributarias y de sus regímenes de inversión extranjera, en función de optar por préstamos y asistencia por parte de este ente financiero; habiendo migrado de una política de desarrollo económico desde la minería, a otra que entrega los recursos naturales no renovables a las fuerzas del mercado.

Si bien la práctica extractiva no es nueva, ni propia del modelo neoliberal, es relevante la exacerbación del accionar de esta industria en las últimas décadas (Armengot et al. 2006; Poveda, 2015), con especial énfasis en los llamados "países del tercer mundo" (Infante, 2011), desde donde se producen materias primas para la importación a los principales países consumidores de estos insumos, muchos de los cuales, privilegian adquirirlos afuera, frente a hacer explotación de recursos de sus propios yacimientos; un ejemplo es el caso de Alemania, país que, en lugar de dedicarse a la extracción mineral, asegura sus materias primas mediante contratos de suministro de largo plazo con países en desarrollo y emergentes (Friess \& Brötz, 2011).

Desde estas lógicas, la acumulación de capital ha implicado explorar los territorios, explotar recursos, excluir a las poblaciones y exterminar, desertificar y destruir el planeta, en beneficio de pocos y ratificando nuevas formas de colonialismo (Almendra, 2016). En este sentido, se trata de una racionalidad incompatible con la vida.

Siguiendo a Verzeñassi (2014), el modelo extractivista (con expresión, entre otras, en la industria minera), afecta la salud y la vida de las poblaciones, su diversidad y su cultura; los usos tradicionales de los territorios, la soberanía alimentaria de las comunidades, las lógicas económicas tradicionales de los pueblos. Este modelo altera las estructuras que posibilitan el equilibrio de los ecosistemas, impacta la calidad del agua que consumimos, del aire. Se trata de una 
Cuadro 2. Impactos de proyectos mineros específicos en algunos países latinoamericanos.

\begin{tabular}{|c|c|c|c|}
\hline País & $\begin{array}{l}\text { Proyecto } \\
\text { minero }\end{array}$ & Principales impactos socioambientales y sanitarios & Referencias \\
\hline Guatemala & Mina Marlin & $\begin{array}{l}\text { Pérdida de acceso a la tierra de comunidades indígenas cercanas a la } \\
\text { mina. } \\
\text { - Transformaciones paisajísticas: cráteres en suelos y descargas de roca } \\
\text { descartada. } \\
\text { - Contaminación de fuentes hídricas, debido a derrame industrial. Muerte } \\
\text { de peces. } \\
\text { - Enfermedades de la piel asociadas a contaminación del agua. } \\
\text { - Niveles elevados de mercurio, cobre, arsénico y zinc en orina. }\end{array}$ & \multirow{10}{*}{$\begin{array}{l}\text { Larios de López et al. 2007; } \\
\text { Fulmer, 2011. Nolasco, } \\
\text { 2011; Marín \& Viales, 2012; } \\
\text { Corrales \& Romero, 2013; } \\
\text { Muñoz \& Texeira, 2013; } \\
\text { Ströbele, 2013; Grupo de } \\
\text { Trabajo sobre Minería y } \\
\text { Derechos Humanos en } \\
\text { América Latina, 2014; } \\
\text { Sibrian \& Van Der Borgh, } \\
\text { 2014; Martínez-Alier, 2015; } \\
\text { Orellana, 2016. }\end{array}$} \\
\hline El Salvador & $\begin{array}{l}\text { Mina San } \\
\text { Sebastián }\end{array}$ & $\begin{array}{l}\text { - Contaminación del río San Sebastián por vertimientos constantes de } \\
\text { drenaje ácido de minas, lo cual, ha dejado sin agua potable a la población } \\
\text { de la zona. } \\
\text { Síntomas de intoxicación como dolores de cabeza, fatiga, afectaciones } \\
\text { en la memoria, siendo las mujeres y niños los más afectados. }\end{array}$ & \\
\hline Honduras & Mina San Andrés & $\begin{array}{l}\text { - Derrames de agua cianurada y demás vertimientos en el río Lara, con las } \\
\text { consecuentes afectaciones sanitarias de la población. } \\
\text { - Presencia de metales pesados en niveles mayores a los permisibles en } \\
\text { fuentes hídricas del territorio. }\end{array}$ & \\
\hline Nicaragua & Mina El limón & $\begin{array}{l}\text { - Contaminación de aguas superficiales y subterráneas, de suelos y } \\
\text { atmósfera. Afectación de la salud de los pobladores. } \\
\text { - } \quad \text { Aumento en la temperatura de las aguas. }\end{array}$ & \\
\hline Costa Rica & Mina Bella Vista & $\begin{array}{l}\text { - Contaminación del río Ciruelas, así como del agua para el consumo } \\
\text { humano. } \\
\text { - Afectación de actividades agropecuarias. }\end{array}$ & \\
\hline Colombia & $\begin{array}{l}\text { Minería en el } \\
\text { cerro sagrado } \\
\text { Care Perro }\end{array}$ & $\begin{array}{l}\text { - Pérdida del paisaje, deforestación, pérdida de cobertura vegetal. } \\
\text { Desnutrición. Problemas mentales como estrés y depresión. Impactos } \\
\text { en la salud relacionados con la violencia (homicidios, violaciones) y con } \\
\text { el alcoholismo y la prostitución. } \\
\text { - Aumento de la corrupción, pérdida de medios de vida y de tradiciones. } \\
\text { Impactos específicos en las mujeres, Violaciones de los derechos } \\
\text { humanos. }\end{array}$ & \\
\hline Brasil & $\begin{array}{l}\text { Minería de } \\
\text { bauxita en Juruti, } \\
\text { Para }\end{array}$ & $\begin{array}{l}\text { - Inseguridad alimentaria por daños a los cultivos, contaminación por } \\
\text { ruido, y del suelo y aguas superficiales y subterráneas, deforestación y } \\
\text { pérdida de cubierta vegetal. } \\
\text { Problemas de salud relacionados con la violencia y con el alcoholismo, } \\
\text { la prostitución y las enfermedades infecciosas. } \\
\text { Desplazamiento, aumento de la violencia y el crimen, impactos } \\
\text { particulares en las mujeres, despojo de tierras. }\end{array}$ & \\
\hline Bolivia & $\begin{array}{l}\text { Extracción de } \\
\text { Litio en el Salar } \\
\text { de Uyuni }\end{array}$ & $\begin{array}{l}\text { - Pérdida paisajística. Contaminación del suelo y de aguas superficiales. } \\
\text { Alteración de la calidad del agua. } \\
\text { Exposición a riesgos complejos, desconocidos o inciertos (como } \\
\text { radiación), enfermedades y accidentes laborales. } \\
\text { - Falta de seguridad laboral, ausentismo, despidos. Pérdida de tradiciones } \\
\text { y del sentido del lugar. }\end{array}$ & \\
\hline Chile & $\begin{array}{l}\text { Minería de litio } \\
\text { en el Salar de } \\
\text { Atacama }\end{array}$ & $\begin{array}{l}\text { - Pérdidas de paisaje. Contaminación y erosión del suelo, contaminación } \\
\text { de las aguas superficiales y subterráneas. } \\
\text { - } \quad \text { Impactos en la salud relacionados a la falta de agua. } \\
\text { - Aumento de la corrupción, pérdida de tradiciones, problemas sociales } \\
\text { como alcoholismo y prostitución, violaciones de los derechos humanos. }\end{array}$ & \\
\hline Argentina & $\begin{array}{l}\text { Exploración de } \\
\text { uranio en Tilcara }\end{array}$ & $\begin{array}{l}\text { Impactos potenciales: } \\
\text { - Contaminación del aire, el suelo y las aguas, pérdida de biodiversidad y } \\
\text { paisajística, inseguridad alimentaria. } \\
\text { - } \quad \text { Exposición a riesgos desconocidos o inciertos como radiación. } \\
\text { Pérdida de medios de vida y de tradiciones, despojo de tierras. }\end{array}$ & \\
\hline
\end{tabular}


transformación de los modos de vida a partir de la colonización de un pensamiento extractivista, soportado en una supuesta "necesidad de progreso" de las poblaciones.

En este escenario, las violaciones de derechos humanos asociadas con el desarrollo de proyectos extractivos están rodeadas de impunidad y las víctimas tienen obstáculos para el acceso a la justicia. Las poblaciones no participan activa y adecuadamente en el diseño y toma de decisiones relacionadas con estos proyectos y, en muchos casos, solo obtienen atención por parte de los gobiernos cuando se gestan situaciones de conflictos graves y formas de violencia, que dificultan la continuación del accionar de las grandes empresas mineras, en contextos en los que la movilización social ha sido objeto de censuras y de criminalización (Alayza, 2009; Grupo de Trabajo sobre Minería y Derechos Humanos en América Latina, 2014). Para Vargas (2014) existen factores que incrementan el riesgo de estos conflictos, tales como la falta de consulta previa, la pobreza y los acuerdos irregulares, por fuera de los términos legales, entre compañías mineras y funcionarios públicos.

Para concluir, la megaminería se ha constituido en un riesgo para la salud y la vida de las personas que habitan las zonas de influencia de los proyectos extractivos, contexto, en el cual, se presentan conflictos entre el interés económico (extractivo) y los intereses sociales. Pese a la promesa de progreso para estas poblaciones, los territorios en los que se lleva a cabo esta actividad a gran escala, son aquellos donde se evidencia (la mayoría de las veces) mayor pobreza (CINEP, 2012; Delgado, 2013; Fierro, 2013). Se trata de comunidades que reciben solo los efectos negativos de estas prácticas y no se benefician de las ganancias económicas derivadas de la explotación y consecuente destrucción de sus territorios de vida.

En este sentido, vale la pena pensar estas lógicas desde una perspectiva de justicia social y ambiental, en contextos de influencia de proyectos de gran minería, en los cuales, las comunidades no obtienen beneficios asociados a las actividades extractivas, sino, más bien, reciben el conjunto de externalidades, los pasivos socioambientales y las afectaciones que esta industria deja a su paso.

Conflictos de intereses: Este manuscrito fue preparado con la participación de todos los autores. Declaramos que no existen conflictos de intereses que pongan en riesgo la consistencia de la información presentada. Financiación: El artículo fue realizado en el marco del proyecto "Cartografía socio-ambiental, perfil epidemiológico en menores de 5 años y estrategia educativa en territorios donde empieza a configurarse la minería como actividad económica: caso Occidente Antioqueño, 2015/2016", financiado por COLCIENCIAS, a través de la convocatoria 657 para proyectos de ciencia, tecnología e innovación en salud. La primera autora también agradece a esta institución, ente financiador de su proceso de formación doctoral (Convocatoria COLCIENCIAS 647 de 2014).

\section{REFERENCIAS}

1. ALAYZA, A. 2009. Minería, comunidades y participación. Consulta y consentimiento previo, libre e informado en el Perú. En: Centro Andino de Acción Popular (CAAP) de Ecuador; Centro Latino Americano de Ecología Social (CLAES) (eds). Extractivismo, política y sociedad. p.157185.

2. ALMENDRA, V. 2016. Colombia: entre el patriarcado extractivista y la Madre Vida. Rev DEP (Colombia). 30:172 188.

3. ANGUlO, L.; HUERTAS, J.; RESTREPO, G. 2011. Caracterización de partículas suspendidas y partículas respirables producidas en áreas de explotación carbonífera a cielo abierto. Información Tecnológica (Chile), 22(4):23-34. http://dx.doi.org/10.4067/S0718-07642011000400004

4. ARMENGOT, J.; ESPÍ, J.; VÁZQUEZ, F. 2006. Orígenes y desarrollo de la minería. Industria y Minería (España). 365:17-28.

5. ASTETE, J.; GASTAÑAGA, M.C.; FIESTAS, V.; OBLITAS, T.; SABASTIZAGAL, I.; LUCERO, M.; ABADÍE, J.M.; MUÑOZ, M.E; VALVERDE, A.; SUÁREZ, M. 2010. Enfermedades transmisibles, salud mental y exposición a contaminantes ambientales en población aledaña al proyecto minero Las Bambas antes de la fase de explotación, Perú 2006. Rev. Peruana de Medicina Experimental y Salud Pública. 27(4):512-519. http:/ / dx.doi.org/10.1590/S172646342010000400004

6. BANCO MUNDIAL. 2013. Minería: Resultados del sector. Disponible desde Internet en: http:/ / www.bancomundial. org/es/results/2013/04/14/mining-results-profile (con acceso el 30/10/2015).

7. BEBBINGTON, A.; HUMPHREYS B., D. 2009. Actores y ambientalismos: conflictos socio-ambientales en Perú. Rev. Íconos (Ecuador). 35:117-128.

8. BENAVIDES, J. 2014. Insumos para el desarrollo del Plan Nacional de Ordenamiento Minero, Ed. Uniandes (Colombia). 846p.

9. BETANCUR, A.; PÉREZ, M. 2016a. Contexto actual de los pueblos indígenas colombianos, ante el desarrollo desmedido de la industria minera en el país. Planeo (Chile). 28:1-11.

10. BETANCUR, A.; PÉREZ, M. 2016b. Desplazados legales o ilegales: una mirada desde los procesos extractivos 
en Colombia y contexto general de algunos países latinoamericanos. Anuario Latinoamericano. Ciencias Políticas y Relaciones Internacionales (Polonia). 3:241-273. http://dx.doi.org/10.17951/al.2016.3.241

11. BOSE-O’REILLY, S.; MCCARTY, K.M.; STECKLING, N.; LETTMEIER, B. 2010. Mercury Exposure and Children's Health. Current Problems in Pediatric and Adolescent Health Care (Estados Unidos). 40(8):186-215. http:// dx.doi.org/10.1016/j.cppeds.2010.07.002

12. CABRERA L., M.; FIERRO M., J. 2013. Implicaciones ambientales y sociales del modelo extractivista en Colombia. En: Garay, L.J. (director). Minería en Colombia. Derechos, políticas públicas y gobernanza. Contraloría General de la República de Colombia. p.89-124.

13. CENTRO DE ESTUDIOS POLÍTICOS PARA LAS RELACIONES INTERNACIONALES Y EL DESARROLLO, CEPRID. 2013. Reflexiones sobre los impactos en derechos humanos de la minería a gran escala en Colombia y américa latina. Disponible desde Internet en: https://www.nodo50.org/ceprid/spip.php?article1591 (con acceso el 30/09/2018).

14. CENTRO DE INVESTIGACIÓN Y EDUCACIÓN POPULAR, CINEP/PROGRAMA POR LA PAZ. 2012. Minería, conflictos sociales y violación de los derechos humanos en Colombia. CINEP (Colombia). 25p.

15. COMISIÓN ECONÓMICA PARA AMÉRICA LATINA Y EL CARIBE, CEPAL. 2015. La Inversión Extranjera Directa en América Latina y el Caribe. Naciones Unidas (Chile). 150p.

16. COMPOSTO, C.; NAVARRO, M. 2012. Estados, transnacionales extractivas y comunidades movilizadas: dominación y resistencias en torno de la minería a gran escala en América Latina. Theomai. (Argentina). 25:58-78.

17. CORRALES, D.; ROMERO, F. 2013. Evaluación de la peligrosidad de jales de zonas mineras de Nicaragua y México y alternativas de solución. Boletín de la Sociedad Geológica Mexicana (México). 65(3):427-446.

18. CORTE CONSTITUCIONAL COLOMBIANA. 2016. Sentencia T-445/16. Disponible desde internet en: https:/ / www.corteconstitucional.gov.co/relatoria/2016/t-445-16. htm

19. CORTE CONSTITUCIONAL COLOMBIANA. 2018. Sentencia SU-095/18. Disponible desde internet en: http://www.corteconstitucional.gov.co/relatoria/2018/ SU095-18.htm
20. DELGADO, G.C. 2010. América Latina y el Caribe como reservas estratégicas de minerales. En: Ecología política de la minería en América Latina aspectos socioeconómicos, legales y ambientales de la mega minería. CLACSO (Argentina). p.17-57.

21. DELGADO, G.C. 2013. Presentación. En: Gentili, P. (Ed.), Ecología Política del extractivismo en America Latina: casos de resistencia y justicia socioambiental. CLACSO (Argentina). p.9-18.

22. FIERRO M., J. 2013. Una aproximación sintética sobre impactos ambientales de la minería no legal. En: Garay, L.J. (director). Minería en Colombia: Institucionalidad y territorio, paradojas y conflictos. Contraloría General de la República de Colombia. p.193-228.

23. FRIESS, S.; BRÖTZ, H. 2011. La minería en los países en desarrollo. Desafíos y propuestas de acción. Misereor (Alemania). 42p.

24. FULMER, A. 2011. La consulta a los pueblos indígenas y su evolución como herramienta de negociación política en América Latina. Los casos de Perú y Guatemala. Apuntes (Perú). 38(68):37-62.

25. GOYZUETA, G.; TRIGOS, C. 2009. Riesgos de salud pública en el centro poblado minero La Rinconada en Puno, Perú. Rev. Peru. Med. Exp. Salud Pública. 26(1):41-44.

26. GRUPO DE INVESTIGACIÓN EN DERECHOS COLECTIVOS Y AMBIENTALES. 2013. Locomotoras normativas anti-ambientalistas: algunos análisis de caso por afectación a derechos colectivos y ambientales. Universidad Nacional de Colombia. 270p.

27. GRUPO DE TRABAJO SOBRE MINERÍA Y DERECHOS HUMANOS EN AMÉRICA LATINA. 2014. El impacto de la minería canadiense en América Latina y la responsabilidad de Canadá. 40p.

28. GUDYNAS, E. 2011. El nuevo extractivismo progresista. En: Gudynas, E. Colonialismos del siglo XXI. Negocios extractivos y defensa del territorio en América Latina. Ed. Icaria (España). p.75-92.

29. IDROVO, A.; MANOTAS, L.; VILLAMIL, G.; ORTIZ, J.; SILVA, E.; ROMERO, S.; AZCÁRATE, C. 2001. Niveles de mercurio y percepción del riesgo en una población minera aurífera del Guainía (Orinoquía colombiana). Biomédica (Colombia). 11:134-141. http://dx.doi.org/10.7705/ biomedica.v21i2.1101

30. INFANTE, C. 2011. Pasivos Ambientales Mineros. Barriendo bajo la alfombra. Ed. Observatorio Conflictos Mineros América Latina. 72p. 
31. INSUASTY R., A.; GRISALES, D.; GUTIÉRREZ L., E. 2013. Conflictos asociados a la gran minería en Antioquia. El Ágora USB (Colombia). 13(2):371-397.

32. ISAZA L., J. 2016. Representaciones sociales del agua en un contexto de conflicto socioambiental por exploración minera - corregimiento de Palocabildo Jericó-Antioquia. Universidad Nacional de Colombia. 215p.

33. ISLA, A. 2002. Forcejeo por mantener el agua limpia y el sustento diario: La minería canadiense en Costa Rica en la era del desarrollo sustentable / globalización. Rev. Ciencias Sociales (Costa Rica). 2002(97):137-147.

34. LARIOS DE LÓPEZ, D.; GUZMÁN, H.; MIRA, E. 2007. Riesgos y posibles impactos de la minería metálica en El Salvador. Rev. Eca. Estudios Centroamericanos (El Salvador). 63(711-712):77-80.

35. LINDÓN, A. 2002. La construcción social del territorio y los modos de vida en la periferia metropolitana. Territorios (Colombia). 7:27-41.

36. MARÍN, J.; VIALES, R. 2012. Los conflictos ecológicodistributivos en Puntarenas: el caso de la mina bellavista de Miramar. Una aproximación inicial. Diálogos: Revista electrónica de historia (Costa Rica). 13(1):243-286.

37. MARTÍNEZ-ALIER, J. 2015. Environmental Justice Atlas. Universidad Autónoma de Barcelona. España. Disponible desde internet en: https://ejatlas.org/featured/blockadia

38. McMAHON, G.; MOREIRA, S. 2014. The Contribution of the Mining Sector to Socioeconomic and Human Development. Banco Mundial. 72p.

39. MONNET, J. 1999. Globalización y territorializaciones areolar y reticular: Los Ángeles y la Ciudad de México J. En: Memorias del V Seminario Internacional de la Red Iberoamericana de Investigadores sobre Globalización y Territorio. Universidad Autónoma del Estado de México. $21 \mathrm{p}$.

40. MUÑOZ, E.; TEXEIRA, W. 2013. Desregulación, conflictos territoriales y movimientos de resistencia: la minería en la Amazonía brasileña. Letras Verdes. Revista Latinoamericana De Estudios Socioambientales (Ecuador). 14:117-138.

41. NOLASCO, S. 2011. Impactos de la minería metálica en Centroamérica. CEICOM. 78p.

42. OLIVERO V., J. 2014. Efectos de la minería en Colombia sobre la salud humana. En: Benavides, J. (comp). Insumos para el desarrollo del Plan Nacional de Ordenamiento Minero. Ed. Uniandes (Colombia). p.493-523.
43. ORELLANA, J. 2016. Evaluación del impacto social, económico y ambiental de la explotación de una empresa minera en las aldeas de San Andrés, San Miguel y Azacualpa, La Unión, Copán, Honduras, marzo de 2015 a febrero de 2016. Revista Ciencia y Tecnología (Costa Rica). 18:153-169. http://doi.org/10.5377/rct.v0i18.3001

44. OROZCO, J.G. 2008. Alcanzar la sustentabilidad ambiental para el logro de los objetivos de desarrollo del Milenio. Rev. Facultad Nacional Salud Pública (Colombia). 26:44-52.

45. OSPINA D., J.M.; GONZÁLEZ J., N.M.; FERNÁNDEZ C., L.J. 2011. Evidencia temprana de alteración funcional por exposición respiratoria: minería artesanal del carbón en Paipa, Colombia. Rev. Facultad Nacional Salud Pública (Colombia). 29(4):445-453.

46. PARDO B., L.A. 2013. Propuestas para recuperar la gobernanza del sector minero colombiano. En: Contraloría de la República de Colombia (ed.). Minería en Colombia. Contraloría de la República de Colombia. p.175-211.

47. PÉREZ OSORNO, M. 2015. Características del contexto territorial que enfrenta hoy en día el centro y sur de América tras la incursión de proyectos mineros en sus naciones. International Journal of Innovation and Scientific Research (Estados Unidos). 25(2):390-398.

48. PÉREZ, M.; BETANCUR, A. 2016a. Impactos ocasionados por el desarrollo de la actividad minera al entorno natural y situación actual de Colombia. Sociedad y Ambiente (México). 10:95-112.

49. PÉREZ, M.; BETANCUR, A. 2016b. Minería resiliente, una alternativa única en materia de protección ambiental contra la industria extractiva y su fuerte tendencia a la destrucción. Monfragüe. Desarrollo Resiliente (España). 7(1):50-72.

50. PÉREZ-RINCÓN, M. 2014. Conflictos ambientales en Colombia: inventario, caracterización y análisis. Disponible desde Internet en: http://censat.org/es/analisis/conflictosambientales-en-colombia-inventario-caracterizacion-yanalisis-2 (con acceso 28/09/2018).

51. POVEDA, G. 2015. Minería en Colombia 1500-2011. Una aproximación histórica. Ed. UNAULA (Colombia). 158p.

52. SAADE, M. 2013. Desarrollo minero y conflictos socioambientales. Los casos de Colombia, México y Perú. Ed. Naciones Unidas (Chile). 57p.

53. SÁNCHEZ, A. 2017. Territorio, extractivismo y (des)ciudadanía en América Latina. El Cotidiano (México). 201:17-26.

54. SÁNCHEZ-ALBAVERA, F.; LARDÉ, J. 2006. Minería y competitividad Internacional en América Latina. Ed. 
CEPAL - División Recursos Naturales e Infraestructura (Chile). 140p.

55. SANDOVAL R., M.L. 2012. Habitus productivo y minería: el caso de Marmato, Caldas. Universitas Humanística (Colombia). 74:145-172.

56. SEOANE, J.; TADDEI, E. 2005. Movimientos sociales, democracia y gobernabilidad neoliberal en América Latina. Aportes Andinos (Ecuador). 13:1-12.

57. SEOANE, J.; TADDEI, E.; ALGRANATI, C. 2013. Extractivismo, despojo y crisis climática. Desafíos para los movimientos sociales y los proyectos emancipatorios de Nuestra América. El Colectivo (Argentina). 336p.

58. SERVICIO DE INFORMACIÓN INDÍGENA, SERVINDI. 2004. La minería y sus impactos. Disponible desde Internet en: https://www.servindi.org/pdf/Serv_57_Mineria.pdf (con acceso 20/06/2018).

59. SIBRIAN, A.; VAN DER BORGH, C. 2014. La Criminalidad de los Derechos: La Resistencia a la Mina Marlin. Oñati Socio-Legal Series. (España). 4(1):63-84.

60. SOLÍZ, M. 2016. Lo que la mina se llevó. Ed. Ediciones de la Tierra (Ecuador). Quito. 167p.

61. STRÖBELE, J. 2013. El proyecto estatal del litio en Bolivia. Expectativas, desafíos y dilemas. Nueva Sociedad (Argentina). 244:74-83.

62. SVAMPA, M. 2007. Movimientos sociales y escenario político: las nuevas inflexiones del paradigma neoliberal en América. En: VI Cumbre del Parlamento Latinoamericano (Venezuela). 15p.
63. SVAMPA, M. 2013. Consenso de los Commodities y lenguajes de valoración en América Latina. Nueva Sociedad (Venezuela). 244:30-46.

64. TORRES, E.; LÓPEZ, M. 2017. Auge minero y desindustrialización en América Latina. Rev. de Economía Institucional (Colombia). 19(37):133-146. http://dx.doi. org/10.18601/01245996.v19n37.07

65. UNIDAD DE PLANEACIÓN MINERO ENERGÉTICA. 2017. Plan Nacional de Desarrollo Minero con horizonte a 2025. Ed. UPME (Colombia).

66. VARGAS, G. 2014. Industria minera y comunidades en Colombia: problemas y recomendaciones. En: Benavides, J. Insumos para el desarrollo del Plan Nacional de Ordenamiento Minero. Ed. Uniandes (Colombia). p.631658.

67. VELTMEYER, H.; PETRAS, J. 2014. El Neoextractivismo. ¿Un modelo posneoliberal de desarrollo o el imperialismo del siglo XXI? Ed. Crítica (México). 400p.

68. VERZEÑASSI, D. 2014. Agroindustria, salud y soberanía. El modelo agrosojero y su impacto en nuestras vidas. En: Melón, D. (ed.). La Patria Sojera. El modelo agrosojero en el Cono Sur. Ed. El Colectivo (Argentina). p.31-48.

69. VIANA RÍOS, R. 2018. Minería en América Latina y el Caribe, un enfoque socioambiental. Rev. U.D.C.A Act. \& Div. Cient. (Colombia). 21(2):617-637. https://doi.org/10.31910/ rudca.v21.n2.2018.1066

70. WALTER, M.; URKIDI A., J. 2014. Consultas comunitarias y vecinales contra la minería metalífera en América Latina (2002-2012). Rev. Ecología Política (España). 48:48-53. 